\title{
Electron mobility in InGaN channel heterostructure field effect transistor structures with different barriers
}

J.Xie

Virginia Commonwealth University

J.H. Leach

Virginia Commonwealth University

X. Ni

Virginia Commonwealth University

See next page for additional authors

Follow this and additional works at: http://scholarscompass.vcu.edu/egre_pubs

Part of the Electrical and Computer Engineering Commons

Xie, J., Leach, J.H., Ni, X., et al. Electron mobility in InGaN channel heterostructure field effect transistor structures with different barriers. Applied Physics Letters, 91, 262102 (2007). Copyright (C 2007 AIP Publishing LLC.

\section{Downloaded from}

http://scholarscompass.vcu.edu/egre_pubs/93

This Article is brought to you for free and open access by the Dept. of Electrical and Computer Engineering at VCU Scholars Compass. It has been accepted for inclusion in Electrical and Computer Engineering Publications by an authorized administrator of VCU Scholars Compass. For more information, please contact libcompass@vcu.edu. 
Authors

J. Xie, J. H. Leach, X. Ni, M. Wu, R. Shimada, Ü. Özgür, and Hadis Morkoç 


\title{
Electron mobility in InGaN channel heterostructure field effect transistor structures with different barriers
}

\author{
J. Xie, ${ }^{\text {a) }}$ J. H. Leach, X. Ni, M. Wu, R. Shimada, Ü. Özgür, and H. Morkoç ${ }^{\text {b) }}$ \\ Department of Electrical and Computer Engineering, Virginia Commonwealth University, Richmond, \\ Virginia 23284, USA
}

(Received 8 October 2007; accepted 23 November 2007; published online 26 December 2007)

\begin{abstract}
InGaN possesses higher electron mobility and velocity than $\mathrm{GaN}$, and therefore is expected to lead to relatively better performances for heterostructure field effect transistors (HFETs). However, the reported mobilities for AlGaN/InGaN HFETs are lower than GaN channel HFETs. To address this issue, we studied the effect of different barriers on the Hall mobility for InGaN channel HFETs grown by metal organic chemical vapor deposition. Unlike the conventional AlGaN barrier, the AlInN barrier can be grown at the same temperature as the InGaN channel layer, alleviating some of the technological roadblocks. Specifically, this avoids possible degradation of the thin InGaN channel during $\mathrm{AlGaN}$ growth at high temperatures; and paves the way for better interfaces. An undoped $\mathrm{In}_{0.18} \mathrm{Al}_{0.82} \mathrm{~N} / \mathrm{AlN} / \mathrm{In}_{0.04} \mathrm{Ga}_{0.96} \mathrm{~N}$ HFET structure exhibited a $\mu_{H}=820 \mathrm{~cm}^{2} / \mathrm{V}$ s, with a $n_{s}$ $=2.12 \times 10^{13} \mathrm{~cm}^{-2}$ at room temperature. Moreover, with an In-doped AlGaN barrier, namely, $\mathrm{Al}_{0.24} \mathrm{In}_{0.01} \mathrm{Ga}_{0.75} \mathrm{~N}$, grown at $900{ }^{\circ} \mathrm{C}$, the $\mu_{H}$ increased to $1230 \mathrm{~cm}^{2} / \mathrm{V} \mathrm{s}$ with a $n_{s}$ of 1.09 $\times 10^{13} \mathrm{~cm}^{-2}$ for a similar InGaN channel. Furthermore, when the barrier was replaced by $\mathrm{Al}_{0.25} \mathrm{Ga}_{0.75} \mathrm{~N}$ grown at $1030{ }^{\circ} \mathrm{C}, \mu_{H}$ dropped to $870 \mathrm{~cm}^{2} / \mathrm{V}$ s with $n_{s}$ of $1.26 \times 10^{13} \mathrm{~cm}^{-2}$ at room temperature. Our results suggest that to fully realize the potential of the InGaN channel HFETs, AlInN or AlInGaN should be used as the barrier instead of the conventional AlGaN barrier. (C) 2007 American Institute of Physics. [DOI: 10.1063/1.2824461]
\end{abstract}

The use of InGaN as the channel for heterostructure field effect transistors (HFETs) is theoretically advantageous over conventional GaN channels because of the relatively high saturation velocities and high sheet carrier densities attainable, which are desirable for high power and high frequency applications. ${ }^{1}$ Maeda et al. ${ }^{2}$ used $\mathrm{AlGaN} / \mathrm{InGaN} / \mathrm{AlGaN}$ double heterostructures (DHs) to improve the confinement of the two-dimensional electron gas (2DEG), and achieved a Hall mobility of $850 \mathrm{~cm}^{2} / \mathrm{V}$ s with a $1.9 \times 10^{13} \mathrm{~cm}^{-2}$ sheet carrier density at room temperature (RT). An InGaN layer (aided by polarization-induced band bending) has also been used as a back barrier in an $\mathrm{AlGaN} / \mathrm{GaN} / \mathrm{InGaN}$ DH to improve the confinement of the 2DEG in the GaN channel. ${ }^{3,4}$ Due to the difficulty of growth, the typical Hall mobility values for InGaN channel HFETS are in the range of $200-850 \mathrm{~cm}^{2} / \mathrm{V} \mathrm{s}$ at RT. ${ }^{5-7}$ Recently, nearly lattice-matched InAlN/GaN HFET structures were reported to improve the performance of GaN-based HFETs. ${ }^{8,9}$ With an AlN spacer, the mobility of an $\operatorname{In}_{0.18} \mathrm{Al}_{0.82} \mathrm{~N} / \mathrm{AlN} / \mathrm{GaN}$ HFET reached $1510 \mathrm{~cm}^{2} / \mathrm{V}$ s at $300 \mathrm{~K}$ and increased to $17600 \mathrm{~cm}^{2} / \mathrm{V} \mathrm{s}$ at $10 \mathrm{~K},{ }^{10}$ which is comparable to that in $\mathrm{AlGaN} / \mathrm{GaN}$ structures. Since the growth temperatures of InGaN and AlInN are similar, it is possible to grow the entire HFET structure (aside from the buffer layer) at a relatively low temperature (below $800{ }^{\circ} \mathrm{C}$ ) and avoid possible degradation, particularly of the channels with a relatively high In composition. Furthermore, the strong spontaneous polarization between In$\mathrm{GaN}$ and AlInN could also provide more carriers than an AlGaN barrier. In addition to the AlInN, the AlInGaN quaternary alloy is also a suitable candidate for the barrier. ${ }^{11}$ In this letter, the $\operatorname{In}_{x} \mathrm{Ga}_{1-x} \mathrm{~N} \quad(x=0.04-0.09)$ channel HFET

\footnotetext{
${ }^{a)}$ Electronic mail: xiej@vcu.edu.

${ }^{b)}$ Electronic mail: hmorkoc@vcu.edu.
}

structures have been studied with $\mathrm{Al}_{1-y} \operatorname{In}_{y} \mathrm{~N}(y=0.16-0.20)$, and $\mathrm{Al}_{0.24} \mathrm{In}_{0.01} \mathrm{Ga}_{0.75} \mathrm{~N}$ (In-doped $\mathrm{AlGaN}$ ) barriers, compared to the $\mathrm{Al}_{0.25} \mathrm{Ga}_{0.75} \mathrm{~N}$ barrier. For a 12-nm-thick $\mathrm{In}_{0.04} \mathrm{Ga}_{0.96} \mathrm{~N}$ channel with an $\mathrm{Al}_{0.82} \mathrm{In}_{0.18} \mathrm{~N}$ barrier, a Hall mobility of $820 \mathrm{~cm}^{2} / \mathrm{V} \mathrm{s}$ and a sheet carrier density of 2.12 $\times 10^{13} \mathrm{~cm}^{-2}$ were measured at room temperature. The room temperature mobility increased to $\mu_{H}=1230 \mathrm{~cm}^{2} / \mathrm{V} \mathrm{s}$ with $n_{s}=1.09 \times 10^{13} \mathrm{~cm}^{-2}$ for the same 12-nm-thick $\operatorname{In}_{0.04} \mathrm{Ga}_{0.96} \mathrm{~N}$ channel with an In-doped $\mathrm{Al}_{0.24} \mathrm{In}_{0.01} \mathrm{Ga}_{0.75} \mathrm{~N}$ barrier.

InGaN channel HFET structures were grown on 2 in. (0001) sapphire substrates in a vertical low-pressure metal organic chemical vapor deposition system. After deposition of a $200 \mathrm{~nm}$ AlN buffer layer at $1050{ }^{\circ} \mathrm{C}$ and $\sim 4 \mu \mathrm{m} \mathrm{GaN}$ at $1000{ }^{\circ} \mathrm{C}$ using $\mathrm{H}_{2}$ as the carrier gas, the wafer was cooled down to $750-800{ }^{\circ} \mathrm{C}$ for $\operatorname{~n}_{x} \mathrm{Ga}_{1-x} \mathrm{~N}$ ( $\left.x=0.04-0.09\right)$ channel and $\mathrm{Al}_{1-y} \mathrm{In}_{y} \mathrm{~N}(y=0.16-0.20)$ barrier growth. The In-doped AlGaN barrier was grown with $\mathrm{N}_{2}$ as the carrier gas at $\sim 900{ }^{\circ} \mathrm{C}$. In all samples, $\sim 1$-nm-thick AlN was used as a spacer layer and $\sim 1 \mathrm{~nm} \mathrm{GaN}$ was used as a cap layer. ${ }^{10}$ The $\sim 1 \mathrm{~nm}$ AlN spacer layer was grown after the InGaN channel growth (with a 3 min interval for changing the carrier gas) at the same temperature. The details of the growth conditions for AlInN can be found in Ref. 10. After the growth, the samples were characterized by high-resolution X-ray diffraction (XRD), atomic force microscopy (AFM), and Hall measurements with a van der Pauw configuration. The In compositions were determined from photoluminescence and XRD measurements using thick (relaxed) calibration layers grown under the same conditions. $\mathrm{Ti} / \mathrm{Al} / \mathrm{Ni} / \mathrm{Au}$ $(300 / 1000 / 300 / 300 \mathrm{~nm})$ metallic layers annealed at $850{ }^{\circ} \mathrm{C}$ were used as the Ohmic contacts for the Hall measurements.

Relatively low growth temperatures (typically $\sim 800^{\circ} \mathrm{C}$ for $\mathrm{Al}_{0.82} \mathrm{In}_{0.18} \mathrm{~N}$ barriers) usually result in abrupt interfaces. For example, compared to the conventional $\mathrm{AlGaN} / \mathrm{GaN}$ 


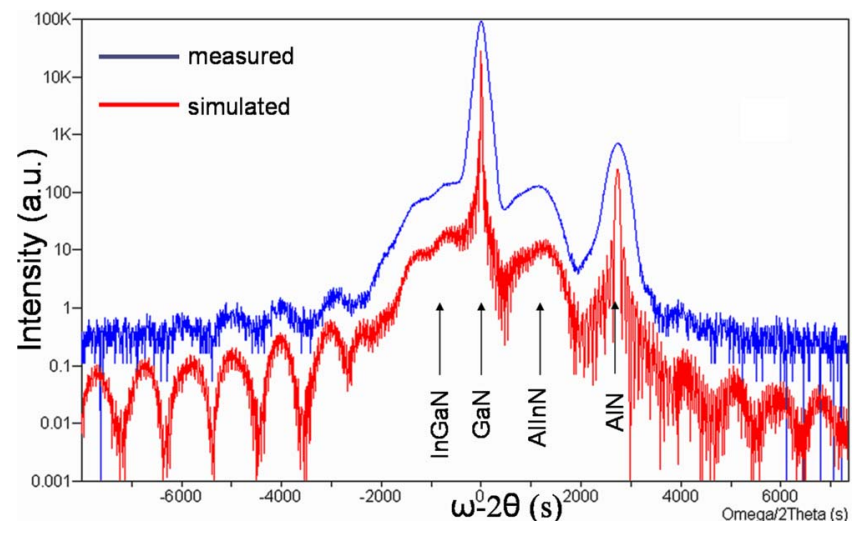

FIG. 1. (Color online) Measured and simulated high-resolution XRD (0002) $\omega$ - $2 \theta$ scans of an $\mathrm{Al}_{0.84} \mathrm{In}_{0.16} \mathrm{~N} / \mathrm{AlN} / \mathrm{In}_{0.09} \mathrm{Ga}_{0.91} \mathrm{~N} / \mathrm{GaN}$ HFET. (12 nm channel, $1 \mathrm{~nm}$ spacer, $17 \mathrm{~nm}$ barrier, and $1 \mathrm{~nm}$ cap.)

HFETs, AlInN/GaN HFETs have much sharper interfaces, as indicated by clear thickness fringes observed in XRD $\omega-2 \theta$ scans by several groups. ${ }^{8-10}$ Similarly, all InGaN channel HFETs investigated here exhibited very clear thickness fringes in XRD $\omega-2 \theta$ scans, as shown in Fig. 1, indicating excellent interface quality. Using the data presented in Fig. 1 together with simulations, the barrier layer thickness for an $\mathrm{Al}_{0.84} \mathrm{In}_{0.16} \mathrm{~N} / \mathrm{AlN} / \mathrm{In}_{0.09} \mathrm{Ga}_{0.91} \mathrm{~N} / \mathrm{GaN}$ structure was determined to be $\sim 17 \mathrm{~nm}$, which is consistent with the calibrated growth rate. Moreover, the diffraction peaks related to the InGaN channel layer appearing at a lower angle than the $\mathrm{GaN}$ buffer are clearly resolved.

In the AlInN/GaN HFET case, the AlN spacer has been reported as being critical to obtaining high mobility by suppressing the alloy scattering from the AlInN barrier. ${ }^{9,10}$ Similar benefits are naturally expected for the AlInN/InGaN/GaN DH HFET structures. Temperature dependent Hall mobilities and sheet carrier densities of four samples having the same $12 \mathrm{~nm} \mathrm{In}_{0.04} \mathrm{Ga}_{0.96} \mathrm{~N}$ channels but different barriers (AlInN or AlGaInN) are plotted in Figs. 2(a) and 2(b), respectively. As shown in Fig. 2(b), when the In $\%$ in the AlInN barrier is decreased from $20 \%$ to $16 \%$, the room temperature sheet carrier density increased from 1.32 $\times 10^{13}$ to $2.29 \times 10^{13} \mathrm{~cm}^{-2}$; however, the mobility decreased from 910 to $630 \mathrm{~cm}^{2} / \mathrm{V} \mathrm{s}$. The increase in the sheet carrier density is mainly due to the increased spontaneous polarization for the AlInN barrier with lower In composition. ${ }^{12}$ The increase in mobility with decreasing sheet carrier concentration is similar to the observation in $\mathrm{AlGaN} / \mathrm{InGaN} / \mathrm{AlGaN}$ DH structures of Maeda et $a l^{2}{ }^{2}$ Moreover, Wang et al. ${ }^{13}$ studied the effect of the channel thickness on the electrical properties in $\mathrm{AlGaN} / \mathrm{In}_{0.1} \mathrm{Ga}_{0.9} \mathrm{~N}$ HFETs, and found that increasing the InGaN channel thickness from 10 to $50 \mathrm{~nm}$ resulted in an $\sim 40 \%$ increase in the sheet carrier density with mobility decreasing from 531 to $266 \mathrm{~cm}^{2} / \mathrm{V}$ s. In our study, when the $\mathrm{In}_{0.04} \mathrm{Ga}_{0.9} \mathrm{~N}$ channel thickness was increased from 12 to $20 \mathrm{~nm}$, the Hall mobility dropped to $490 \mathrm{~cm}^{2} / \mathrm{V} \mathrm{s}$ without any noticeable change in the sheet carrier density at $300 \mathrm{~K}$ (see Table I). This is because of the use of an AlInN barrier instead of $\mathrm{AlGaN}$, and the sheet carrier density is mainly determined by the spontaneous polarization. ${ }^{12}$ It should be noted that Hall mobilities at low temperature for all the InGaN channel HFETs are much lower than those for GaN channel HFETs with similar AllnN barriers ${ }^{\text {it }}$ due to the

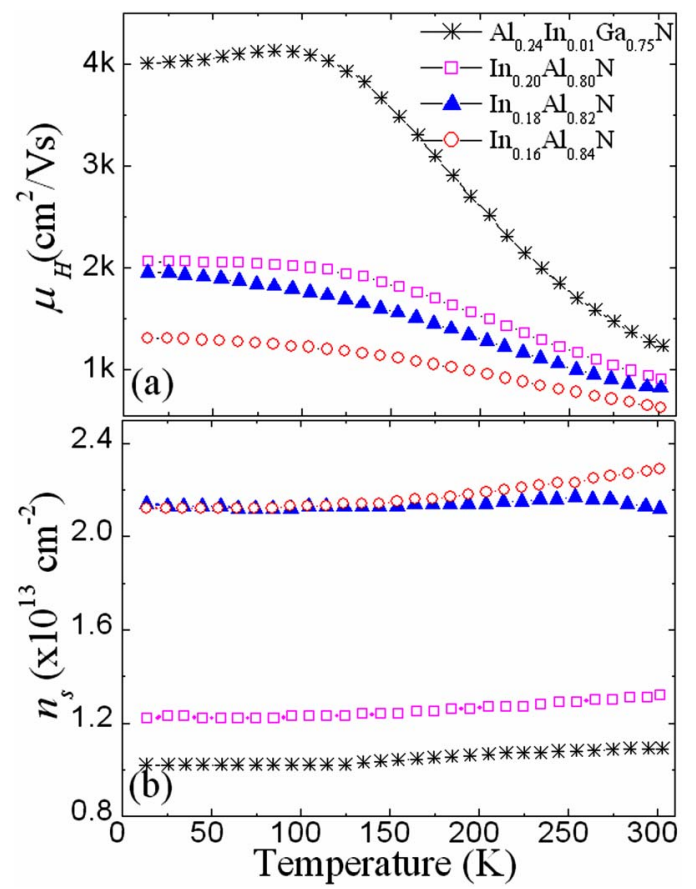

FIG. 2. (Color online) Temperature dependent (a) Hall mobility and (b) sheet carrier density for the $12 \mathrm{~nm} \operatorname{In}_{0.04} \mathrm{Ga}_{0.96} \mathrm{~N}$ HFETs with different barriers.

increasing contribution by alloy scattering in the channel itself, ${ }^{1}$ and the unoptimized AlN spacer.

Wang et al. ${ }^{14}$ reported that $\mathrm{AlGaN} / \mathrm{InGaN} / \mathrm{GaN} \mathrm{DH}$ structures had rougher surfaces than $\mathrm{AlGaN} / \mathrm{GaN}$ HFET structures, because of the instability of the InGaN surface at high temperatures $\left(>1000{ }^{\circ} \mathrm{C}\right)$. Moreover, the roughness increases for structures with barriers having higher $\mathrm{Al}$ compositions, which reduces the mobility by interface scattering. ${ }^{14}$ As listed in Table I, the rms roughness values, taken over a $5 \times 5 \mu \mathrm{m}^{2}$ area and measured by AFM, for InGaN channel HFETs are in the range of $0.38-0.97 \mathrm{~nm}$, all of which are higher than the typical values of $0.30 \mathrm{~nm}$ for $\mathrm{GaN}$ channel HFETs. Increased interface roughness and alloy scattering in the channel, especially for the channel with $9 \%$ In, are probably the dominant mechanisms limiting the electron mobility in InGaN channel HFETs at low temperatures. However, for the InGaN channel case, the difficulties in growing $\mathrm{InGaN}$, such as significant phase separation, should also be considered. In GaN/InGaN multiple quantum wells (MQWs), indium segregation and diffusion along the dislocation cores have been observed. ${ }^{15}$ Thus, In fluctuations become significantly pronounced in the vicinity of dislocations, which would pose a particular problem for samples with high threading dislocation (TD) densities. Considering our samples, which have a TD density in the mid- $10^{9}-\mathrm{cm}^{-2}$ range (as estimated from XRD symmetric and asymmetric rocking curves and AFM measurements), the Hall mobility would be under the strong influence of indium fluctuations. Moreover, anomalous pulling effect, ${ }^{16}$ which results in indium composition fluctuation along the growth direction, was observed in InGaN/GaN MQWs. Therefore, the short-range potential barrier scattering ${ }^{17}$ (in addition to the alloy scattering) and the localization effects ${ }^{18}$ in the InGaN channels are much stronger than in GaN channels, which lower the electron mobility at room temperature. Based on the discussion above, considering the sample with a $20 \mathrm{~nm}^{2} \ln _{0.04} \mathrm{Ga}_{0.96} \mathrm{~N}$ channel 
TABLE I. Measured rms surface roughness, $\mu_{H}$, and $n_{s}$ for $\operatorname{In}_{x} \mathrm{Ga}_{1-x} \mathrm{~N}$ channel HFETs at 300 and $10 \mathrm{~K}$.

\begin{tabular}{|c|c|c|c|c|c|c|c|}
\hline \multicolumn{2}{|c|}{$\begin{array}{c}\mathrm{In}_{x} \mathrm{Ga}_{1-x} \mathrm{~N} \\
\text { channel }\end{array}$} & \multirow{2}{*}{$\begin{array}{c}\begin{array}{c}\mathrm{Al}_{1-y} \mathrm{In}_{y} \mathrm{~N} \\
\text { barrier }\end{array} \\
\operatorname{In}(\%)\end{array}$} & \multirow{2}{*}{$\begin{array}{l}\mathrm{rms} \\
(\mathrm{nm})\end{array}$} & \multicolumn{2}{|c|}{$\begin{array}{c}\mu_{\text {Hall }} \\
\left(\mathrm{cm}^{2} / \mathrm{V} \mathrm{s}\right)\end{array}$} & \multicolumn{2}{|c|}{$\begin{array}{c}n_{s} \\
\left(10^{13} \mathrm{~cm}^{-2}\right)\end{array}$} \\
\hline In $(\%)$ & $d(\mathrm{~nm})$ & & & $300 \mathrm{~K}$ & $10 \mathrm{~K}$ & $300 \mathrm{~K}$ & $10 \mathrm{~K}$ \\
\hline 4 & 12 & 16 & 0.43 & 630 & 1310 & 2.29 & 2.12 \\
\hline 4 & 12 & 18 & 0.54 & 820 & 1950 & 2.12 & 2.14 \\
\hline 4 & 12 & 20 & 0.38 & 910 & 2060 & 1.32 & 1.22 \\
\hline 4 & 20 & 18 & 0.45 & 490 & 690 & 2.15 & 1.93 \\
\hline 9 & 12 & 16 & 0.97 & 390 & & 2.78 & \\
\hline 4 & 12 & $\mathrm{Al}_{0.24} \mathrm{In}_{0.01} \mathrm{Ga}_{0.75} \mathrm{~N}$ & 0.62 & 1230 & 4006 & 1.09 & 1.02 \\
\hline 4 & 12 & $\mathrm{Al}_{0.25} \mathrm{Ga}_{0.75} \mathrm{~N}$ & 0.79 & 870 & & 1.26 & \\
\hline \multicolumn{2}{|c|}{ GaN channel } & $\mathrm{Al}_{0.25} \mathrm{Ga}_{0.75} \mathrm{~N}$ & 0.28 & 1350 & 14550 & 0.86 & 0.88 \\
\hline \multicolumn{2}{|c|}{ GaN channel ${ }^{\mathrm{a}}$} & $\mathrm{Al}_{0.82} \mathrm{In}_{0.18} \mathrm{~N}$ & 0.30 & 1510 & 17600 & 1.16 & 0.96 \\
\hline
\end{tabular}

${ }^{\mathrm{a}}$ Reference 10.

(see Table I), which has a surface roughness similar to that in other samples with $4 \%$ In, the reduction of the mobility with increasing channel thickness is possibly due to the degradation of the quality of the channel. Plausibly for the same reason, Okamoto et al. ${ }^{19}$ observed a dramatic increase of the Hall mobility from $\sim 500$ to $\sim 1110 \mathrm{~cm}^{2} / \mathrm{V} \mathrm{s}$ in $\mathrm{Al}_{0.3} \mathrm{Ga}_{0.7} \mathrm{~N} / \mathrm{In}_{0.06} \mathrm{Ga}_{0.94} \mathrm{~N} / \mathrm{GaN}$ structures when the InGaN channel thickness decreased from 15 to $3 \mathrm{~nm}$, respectively. Therefore, to achieve high electron mobility, the InGaN channel should be kept thin, and even more importantly, GaN templates with low dislocation densities should be used.

To further study electron transport affected by the barrier in InGaN channel HFETs, we also prepared two HFET samples: one with an In-doped AlGaN barrier, namely, $\mathrm{Al}_{0.24} \mathrm{In}_{0.01} \mathrm{Ga}_{0.75} \mathrm{~N}$, and the other with a conventional $\mathrm{Al}_{0.25} \mathrm{Ga}_{0.75} \mathrm{~N}$ barrier as a reference, for the same $12 \mathrm{~nm}$ $\mathrm{In}_{0.04} \mathrm{Ga}_{0.96} \mathrm{~N}$ channel. Also, $\sim 1$-nm-thick AlN spacers were incorporated after the InGaN channels at $\sim 800{ }^{\circ} \mathrm{C}$ for protecting the channel surface. After that, the $\mathrm{Al}_{0.24} \mathrm{In}_{0.01} \mathrm{Ga}_{0.75} \mathrm{~N}$ barrier was deposited at $\sim 900{ }^{\circ} \mathrm{C}$ with pure nitrogen carrier gas, while the $\mathrm{Al}_{0.25} \mathrm{Ga}_{0.75} \mathrm{~N}$ barrier was deposited at $\sim 1030{ }^{\circ} \mathrm{C}$ with pure $\mathrm{H}_{2}$ carrier gas. AFM studies showed that surface pits similar to the well-known dislocation-related "V defects" in InGaN/GaN MQWs. ${ }^{20}$ RT Hall measurement showed that the mobility reached $1230 \mathrm{~cm}^{2} / \mathrm{V} \mathrm{s}$ with a $1.09 \times 10^{13} \mathrm{~cm}^{-2}$ sheet density for the sample having $\mathrm{Al}_{0.24} \mathrm{In}_{0.01} \mathrm{Ga}_{0.75} \mathrm{~N}$ barrier, and $870 \mathrm{~cm}^{2} / \mathrm{V} \mathrm{s}$ with 1.26 $\times 10^{13} \mathrm{~cm}^{-2}$ sheet density for the sample having $\mathrm{Al}_{0.25} \mathrm{Ga}_{0.75} \mathrm{~N}$ barrier. Moreover, with the $\mathrm{Al}_{0.24} \mathrm{In}_{0.01} \mathrm{Ga}_{0.75} \mathrm{~N}$ barrier, mobility increased to $4006 \mathrm{~cm}^{2} / \mathrm{V}$ s at $10 \mathrm{~K}$ (see Fig. 2). Our results suggest that a high electron mobility can be achieved in the InGaN channel if a proper barrier is used.

In conclusion, we reported the electron mobility in InGaN channel HFETs with different barriers. With the proper barrier, such as $\mathrm{Al}_{0.24} \mathrm{In}_{0.01} \mathrm{Ga}_{0.75} \mathrm{~N}$, the HFET containing a $12 \mathrm{~nm} \operatorname{In}_{0.04} \mathrm{Ga}_{0.96} \mathrm{~N}$ channel exhibited a $1230 \mathrm{~cm}^{2} / \mathrm{V}$ s Hall mobility at room temperature. Our results suggest that utilizing AlInN or AlInGaN (In-doped AlGaN), instead of the conventional $\mathrm{AlGaN}$ as the barrier, would be helpful toward the realization of InGaN channel HFETs.
This work has been funded by a grant from the Air Force Office of Scientific Research (Dr. Kitt Reinhardt and Dr. Donald Silversmith).

${ }^{1}$ H. Morkoç, Handbook of Nitride Semiconductors and Devices (WileyVCH, New York, in press), Vol. III.

${ }^{2}$ N. Maeda, T. Saitoh, K. Tsubaki, T. Nishida, and N. Kobayashi, Jpn. J. Appl. Phys., Part 2 38, L799 (1999).

${ }^{3}$ J. Liu, Y. Zhou, J. Zhu, K. M. Lau, and K. J. Chen, IEEE Electron Device Lett. 27, 10 (2006).

${ }^{4}$ T. Palacios, A. Chakraborty, S. Heikman, S. Keller, S. P. DenBaars, and U. K. Mishra, IEEE Electron Device Lett. 27, 13 (2006).

${ }^{5}$ C. X. Wang, K. Tsubaki, N. Kobayashi, T. Makimoto, and N. Maeda, Appl. Phys. Lett. 84, 2313 (2004).

${ }^{6}$ G. Simin, A. Koudymov, H. Fatima, J. Zhang, J. Yang, M. A. Khan, X. Hu, A. Tarakji, R. Gaska, and M. S. Shur, IEEE Electron Device Lett. 23, 458 (2002).

${ }^{7}$ W. Lanford, V. Kumar, R. Schwindt, A. Kuliev, I. Adesida, A. M. Dabiran, A. M. Wowchak, P. P. Chow, and J.-W. Lee, Electron. Lett. 40, 771 (2004).

${ }^{8}$ A. Dadgar, F. Schulze, J. Bläsing, A. Diez, A. Krost, M. Neuburger, E. Kohn, I. Daumiller, and M. Kunze, Appl. Phys. Lett. 85, 5400 (2004).

${ }^{9}$ M. Gonschorek, J.-F. Carlin, E. Feltin, M. A. Py, and N. Grandjean, Appl. Phys. Lett. 89, 062106 (2006).

${ }^{10}$ J. Xie, X. Ni, M. Wu, J. H. Leach, Ü. Özgür, and H. Morkoç, Appl. Phys. Lett. 91, 132116 (2007).

${ }^{11}$ Y. Liu, H. Jiang, S. Arulkumaran, T. Egawa, B. Zhang, and H. Ishikawa, Appl. Phys. Lett. 86, 223510 (2006).

${ }^{12}$ J. Kuzmík, IEEE Electron Device Lett. 22, 510 (2001).

${ }^{13}$ R.-L. Wang, Y.-K. Su, and K.-Y. Chen, Electron. Lett. 42, 718 (2006).

${ }^{14}$ C. X. Wang, K. Tsubaki, N. Kobayashi, T. Makimoto, and N. Maeda, Appl. Phys. Lett. 84, 2313 (2004).

${ }^{15}$ N. Duxbury, U. Bangert, P. Dawson, E. J. Thrush, W. Van Der Stricht, K. Jacobs, and I. Moerman, Appl. Phys. Lett. 76, 1600 (2000).

${ }^{16}$ M. Hao, H. Ishikawa, T. Egawa, C. L. Shao, and T. Jimbo, Appl. Phys. Lett. 82, 4702 (2003).

${ }^{17}$ H. Morkoç, Handbook of Nitride Semiconductors and Devices (Wiley$\mathrm{VCH}$, New York, in press), Vol. II.

${ }^{18}$ S. F. Chichibu, K. Wada, J. Müllhäuser, O. Brandt, K. H. Ploog, T. Mizutani, A. Setoguchi, R. Nakai, M. Sugiyama, H. Nakanishi, K. Korii, T. Deguchi, T. Sota, and S. Nakamura, Appl. Phys. Lett. 76, 1671 (2000).

${ }^{19}$ N. Okamoto, K. Hoshino, N. Hara, M. Takikawa, and Y. Arakawa, J. Cryst. Growth 272, 278 (2004).

${ }^{20}$ X. H. Wu, C. R. Elsass, A. Abare, M. Mack, S. Keller, P. M. Petroff, S. P. DenBaars, J. S. Speck, and S. J. Rosner, Appl. Phys. Lett. 72, 692 (1998). 